\title{
Electroporation of DNA into Physarum polycephalum Mitochondria: Effects on Transcription and RNA Editing in Isolated Organelles
}

\author{
Jonatha M. Gott ${ }^{1, *}$, Gregory M. Naegele ${ }^{1, \dagger}$ and Scott J. Howell ${ }^{2}$ \\ 1 Center for RNA Molecular Biology, Case Western Reserve University, Cleveland, OH 44120, USA; \\ gmnaegele@gmail.com \\ 2 Visual Sciences Research Center, Case Western Reserve University, Cleveland, OH 44120, USA; \\ sjh36@case.edu \\ * Correspondence: jmg13@case.edu \\ + Current address: Department of Stem Cell Biology and Regenerative Medicine, Lerner Research Institute, \\ Cleveland Clinic, Cleveland, OH 44195, USA.
}

Academic Editor: H. Ulrich Göringer

Received: 31 October 2016; Accepted: 5 December 2016; Published: 14 December 2016

\begin{abstract}
Mitochondrial RNAs in the acellular slime mold Physarum polycephalum contain nucleotides that are not encoded in the mitochondrial genes from which they are transcribed. These site-specific changes are quite extensive, comprising $\sim 4 \%$ of the residues within mRNAs and $\sim 2 \%$ of rRNAs and tRNAs. These "extra" nucleotides are added co-transcriptionally, but the means by which this is accomplished have not been elucidated. The cox $1 \mathrm{mRNA}$ also contains four sites of $\mathrm{C}$ to $\mathrm{U}$ changes, which occur post-transcriptionally, most likely via targeted deamination. The currently available in vitro systems for studying $P$. polycephalum editing are limited in that the template is the entire $\sim 63,000 \mathrm{bp}$ mitochondrial genome. This presents a significant challenge when trying to define the signals that specify editing sites. In an attempt to overcome this issue, a method for introducing DNA into isolated P. polycephalum mitochondria via electroporation has been developed. Exogenous DNA is expressed, but the transcripts synthesized from these templates are not edited under the conditions tested. However, transcripts derived from the mitochondrial genome are accurately edited after electroporation, indicating that the editing machinery is still functional. These findings suggest that this method may ultimately provide a feasible approach to elucidating editing signals.
\end{abstract}

Keywords: RNA editing; Physarum polycephalum; mitochondria; electroporation

\section{Introduction}

Many species produce RNAs whose sequences differ from the DNA from which they are transcribed. The processes that result in these site-specific alterations are collectively referred to as RNA editing [1]. Editing mechanisms vary widely, resulting in changes at either the base or nucleotide level [2]. Mitochondrial RNAs are extensively edited in a number of organisms. Maturation of higher plant mitochondrial RNAs involves hundreds of $C$ to $U$ changes resulting from targeted post-transcriptional deamination reactions, while some lower plant mitochondrial RNAs contain thousands of $C$ to $U$ changes and hundreds of $U$ to $C$ changes [3]. Base changes of multiple types are also prevalent in mitochondrial RNAs in certain dinoflagellates [4,5], although the underlying mechanism remains unclear. Widespread changes at the nucleotide level occur in the mitochondria of kinetoplastid protozoa and myxomycetes. Kinetoplast RNAs are processed by a series of guide RNA-directed cleavage and ligation reactions, resulting in the insertion of thousands of added uridines and removal of hundreds of encoded Us [6], while over 1300 non-encoded nucleotides are added to mitochondrial RNAs in Physarum polycephalum [7]. 
At least three distinct RNA editing mechanisms are used during mitochondrial gene expression in P. polycephalum [8]. The majority of editing events in P. polycephalum mitochondria involve the precise insertion of non-encoded nucleotides (nt), 95\% (1255 of $1324 \mathrm{nt}$ ) of which are single C insertions. Other ribonucleotides are also added at a limited number of defined sites, either singly or in pairs. Rarer forms of editing include a deletion of three encoded A residues [9], the replacement of the $5^{\prime}$ nucleotide of two mitochondrial tRNAs [10], and four C to U changes [11]. In total, site-specific changes are present in 37 of the 39 mRNAs, all three rRNAs, and the five tRNAs encoded in the P. polycephalum mitochondrial genome. Editing is extremely accurate and highly efficient based on both characterization of transcripts from individual genes [9-16] and sequencing of the entire mitochondrial transcriptome [7].

The mechanism of nucleotide insertion in P. polycephalum mitochondria is distinct from the guide RNA-directed $U$ insertion/deletion form of editing described in trypanosomes and the polymerase stuttering utilized in viral systems [17]. We are interested in elucidating the cis-acting elements and trans-acting factors involved in RNA sequence alterations within P. polycephalum mitochondria, and have established two in vitro systems in which to study editing, both of which rely on transcription/editing complexes formed in vivo $[18,19]$. Using these systems, we have demonstrated that insertion editing occurs co-transcriptionally, i.e., the extra nucleotides are added at the $3^{\prime}$ end of the nascent RNA during synthesis [17], and that the template elements required for the insertion of non-encoded nucleotides are limited to $\sim 18$ base pairs (bp) centered around the editing site [20]. However, in order to definitively identify the cis-elements that direct editing of P. polycephalum mitochondrial transcripts, it will be necessary to achieve transcription and editing from a template that can be easily manipulated in vitro.

Electroporation has been used previously to introduce DNA into isolated mitochondria. An early study using mammalian mitochondria demonstrated DNA uptake and the effects of field strength on mitochondrial function, but did not examine transcriptional activity [21]. This methodology was subsequently adapted to study transcription, splicing, and RNA editing in mitochondria from wheat [22-27], maize and sorghum [28,29], and potato [30,31]. Accurate $C$ to $U$ editing of transcripts derived from chimeric genes was observed in each of these systems, allowing localization of the cis-acting signals essential for editing [22,25].

Here we describe the development of methods for the introduction of DNA into P. polycephalum mitochondria and provide evidence that exogenous DNA is expressed, albeit at low levels. In these initial studies, no evidence of either nucleotide insertion or $\mathrm{C}$ to $\mathrm{U}$ changes was observed in transcripts from the introduced templates. However, transcription from endogenous genes is not significantly affected by electroporation at moderate field strengths, and the transcripts synthesized from the mitochondrial genome after electroporation are still largely edited. Thus, the editing apparatus is not inactivated under these conditions, providing a starting point for future investigations of editing signals.

\section{Materials and Methods}

\subsection{DNAs Used for Electroporation}

All plasmids used in this study contained the promoter region that drives transcription of the mitochondrial ribosomal RNA genes (large and small subunit rRNAs and 5S rRNA). The plasmid (\#809) used in the experiments in Figure 1, Figure 2B, and Figure S1 contains the entire 125 bp intergenic region upstream of the $P$. polycephalum mitochondrial large subunit rRNA (LSU) gene and $97 \mathrm{bp}$ of the transcribed portion of the LSU gene fused via a linker to $445 \mathrm{bp}$ derived from the P. polycephalum mitochondrial cox1 gene and inserted into the HindIII and EcoRI sites of vector pBSM13+ (Agilent Technologies, Santa Clara, CA, USA). The linker sequence provides a unique primer binding site which, along with the 5 bp block mutation introduced near the $3^{\prime}$ end of the cox 1 portion (shown in Figure S1), ensures that reverse transcription PCR (RT-PCR) products derived from fusion 
gene transcripts can be distinguished from those arising from the endogenous cox 1 gene. The $847 \mathrm{bp}$ PCR product used in the experiments shown in Figures 1 and 2A contained the entire insert plus flanking sequences derived from the vector. The PCR product was purified using a QIAquick PCR purification kit (Qiagen, Germantown, MD, USA) followed by passage through a Micro Bio-Spin P30 column (Bio Rad, Hercules, CA, USA), concentrated via ethanol precipitation, and resuspended in PCR-grade water at a final concentration of $0.5 \mu \mathrm{g} / \mu \mathrm{L}$ prior to electroporation. The plasmid used in the experiment shown in Figure 3 (\#819) contains the entire $125 \mathrm{bp}$ intergenic region upstream of the P. polycephalum mitochondrial LSU gene and $15 \mathrm{bp}$ of the transcribed portion of the LSU gene inserted into the HindIII and SalI sites of pBSM13+. The LSU gene was omitted from the dot blot to avoid potential hybridization to $L S U$-vector fusion transcripts. The plasmid used in the experiment shown in Figure 4 (\#802) contains $70 \mathrm{bp}$ of the intergenic region immediately upstream of the P. polycephalum mitochondrial LSU gene and $97 \mathrm{bp}$ of the transcribed portion of the LSU gene inserted into the PstI and $\mathrm{XbaI}$ sites of $\mathrm{pBSM} 13+$.

\subsection{Mitochondrial Isolation}

Although P. polycephalum mitochondria isolated via differential centrifugation synthesize run-on transcripts that are fully edited, when further purified on Percoll (GE Healthcare Life Sciences, Pittsburgh, PA, USA) gradients, few sediment at the appropriate density, resulting in very low yields. To enhance mitochondrial yields, we explored a broad range of conditions, ultimately arriving at the conditions described below. The mitochondria in these preparations are uniform in size and essentially free of nuclei, pigment granules, and other contaminants (Figure 1, left). They are also transcriptionally active and synthesize edited RNAs (see Results).

Microplasmodia were cultured at $26{ }^{\circ} \mathrm{C}$ in $300 \mathrm{~mL}$ SDM medium [32] in a 2-L baffled flask to mid-log phase, then poured into a large beaker on ice and allowed to settle by gravity. The medium was decanted and the cells washed by swirling gently in $300 \mathrm{~mL}$ ice-cold sclerotia salts (19 $\mathrm{mM}$ citric acid, $0.3 \mathrm{mM} \mathrm{FeCl}_{2}, 2.4 \mathrm{mM} \mathrm{MgSO}_{4}, 8.1 \mathrm{mM} \mathrm{CaCl}_{2}, 0.4 \mathrm{mM} \mathrm{MnCl}_{2}, 0.1 \mathrm{mM} \mathrm{ZnSO}_{4}, 2.9 \mathrm{mM} \mathrm{KH}_{2} \mathrm{PO}_{4}$, pH 4.8) [33]. The liquid was again decanted and the cells were resuspended in $75 \mathrm{~mL}$ ice-cold sclerotia salts and split evenly into two $50 \mathrm{~mL}$ conical tubes. Cells were pelleted by centrifugation for $2 \mathrm{~min}$ at $\sim 800 \times g$ and the liquid was again decanted. Each pellet was washed twice with sterile ice cold distilled water, vortexing gently and pelleting as above. After removing as much liquid as possible, cells were transferred to a $55 \mathrm{~mL}$ Wheaton homogenizer (Millville, NJ, USA) on ice, rinsing the tubes with $15 \mathrm{~mL}$ of ice cold buffered sucrose (BSS, $10 \mathrm{mM}$ Tris ( $\mathrm{pH}$ 7.5)/0.25 M sucrose). Cells were broken open by douncing for 5 strokes and $\alpha$-amylase was added to the lysate at a final concentration of $40-80 \mu \mathrm{g} / \mathrm{mL}$. After $10 \mathrm{~min}$ on ice, cells were dounced another 5 strokes and the homogenate was examined using phase contrast microscopy to determine if additional strokes were needed. The lysate was then filtered to remove residual clumps and slime prior to layering over Percoll gradients consisting of steps of $1.082,1.062$, and $1.044 \mathrm{~g} / \mathrm{mL}$ in $2 \mathrm{mM}$ Tris ( $\mathrm{pH} 7.5) / 0.25 \mathrm{M}$ sucrose. Gradients were centrifuged for $1 \mathrm{~min}$ at $25,000 \times \mathrm{g}$ and the mitochondrial bands were transferred to a fresh tube. Mitochondria were then diluted by slowly layering 2.5 volumes of $2 \mathrm{mM}$ Tris ( $\mathrm{pH} 7.5) / 0.25 \mathrm{M}$ sucrose with gentle mixing prior to centrifugation at $7600 \times \mathrm{g}$ for $10 \mathrm{~min}$ at $4{ }^{\circ} \mathrm{C}$. Mitochondria were resuspended in $0.33 \mathrm{M}$ sucrose and the protein content was determined (Bio-Rad Protein Assay) prior to pelleting at $5100 \times g$ for $5 \mathrm{~min}$ at $4{ }^{\circ} \mathrm{C}$. The final mitochondrial pellets were resuspended in $0.33 \mathrm{M}$ sucrose and kept on ice until use.

\subsection{Electroporation}

Mitochondria at protein concentrations of $5-10 \mu \mathrm{g} / \mu \mathrm{L}$ were split into $50 \mu \mathrm{L}$ aliquots and mixed with plasmid DNA $(0.5-1 \mu \mathrm{g})$ or purified PCR fragment (30-500 $\mathrm{ng}$ ) as appropriate. Mitochondria were then transferred to a cold $0.1 \mathrm{~cm}$ gap electroporation cuvette (Bio Rad) and electroporated using an Eppendorf Electroporator 2510 (Hauppauge, NY, USA) at $10 \mu \mathrm{F}, 600 \Omega$, and field strengths between $5 \mathrm{kV} / \mathrm{cm}$ and $20 \mathrm{kV} / \mathrm{cm}$. The samples were immediately transferred to a fresh tube and the cuvette was rinsed with $50 \mu \mathrm{L} 0.33 \mathrm{M}$ sucrose, which was added to the sample. Samples were then used for microscopy and/or transcription and editing assays as noted. 


\subsection{Microscopy}

Mitochondria were concentrated by pelleting and resuspended in $0.33 \mathrm{M}$ sucrose prior to microscopy. Images were collected with a Retiga EXI camera (Q-imaging Vancouver, BC, Canada) mounted on a Leica DMI 6000 B inverted microscope (Leica Biosystems, Wetzlar, Germany) using a $63 \times$ objective (1.4 NA Plan Apo) with a $1.6 \times$ mag changer for a resulting magnification of $1008 \times$. Mitochondria were visualized using phase contrast optics. Fluorescent DNA was visualized using a standard Texas Red filter set. Equal thresholds were set to detect only the brightest fluorescent signals. These signals were then outlined and overlaid onto the phase image. The co-localization of fluorescence and mitochondria is indicated by colored outlines in the overlay image.

\subsection{Transcription, $R T-P C R$, and $P C R$}

Transcription reactions with unlabeled nucleotides were carried out in $0.3-0.33 \mathrm{M}$ sucrose $/ 20 \mathrm{mM}$ Tris ( $\mathrm{pH} 7.5) / 20 \mathrm{mM} \mathrm{MgCl} / 2 / 10 \mathrm{mM} \mathrm{KCl} / 2 \mathrm{mM}$ DTT/500 $\mu \mathrm{M}$ NTPs. Mitochondria were pelleted and resuspended in Trizol Reagent (Invitrogen/Thermo Fisher Scientific, Waltham, MA, USA) and RNAs were isolated as specified by the supplier. The resulting RNA pellets were resuspended in $10 \mathrm{mM}$ Tris (pH 7.5)/1 mM EDTA, extracted with 24:1 chloroform: isoamyl alcohol (CIA), and ethanol precipitated. To avoid background signal from residual exogenous DNA in subsequent PCR reactions, RNA preparations were subsequently incubated with EcoRI (New England Biolabs, Ipswich, MA, USA) to remove the primer binding sites for the reverse transcription and PCR reactions, CIA extracted, and ethanol precipitated prior to two rounds of DNase I (Roche, Indianapolis, IN, USA) treatment. Parallel complementary DNA (cDNA) synthesis reactions were carried out by annealing a primer complementary to sequences specific for the exogenous DNA (\#508: GGTTTTCCCAGTCACGAC), then splitting each annealed RNA/primer mix into two equal aliquots, incubating under reaction conditions that were identical except for the presence or absence of AMV reverse transcriptase (Life Sciences, Saint Petersburg, FL, USA). Subsequent PCR reactions were carried out with primers \#494 (TGTAAAACGACGGCCAGTG) and \#505 (CTAGATCTGGGTCGTTGTC), yielding a 538 bp fragment (Figure 2). No signal was observed in the absence of added DNA, indicating that endogenous RNA does not yield a product with these primers (Figure 2B). The $847 \mathrm{bp}$ PCR product used for electroporation (Figures 1 and 2A) was generated from plasmid \#809 using primers \#508 (GGTTTTCCCAGTCACGAC) and \#509 (5'-cy3-GAAACAGCTATGACCATG). PCR fragments for dot blots were generated using the primers listed in Table S1. All PCR products were generated with Taq DNA polymerase (New England Biolabs) under conditions specified by the supplier.

\subsection{Dot Blot Experiments}

PCR fragments to be immobilized on nitrocellulose filters were heated to $95{ }^{\circ} \mathrm{C}$ for $5 \mathrm{~min}$, snap-cooled on ice, then incubated in $0.5 \mathrm{M} \mathrm{NaOH}$ for $10 \mathrm{~min}$ on ice. Samples were neutralized by the addition of one-half volume of neutralization solution $[0.5 \mathrm{M}$ Tris- $\mathrm{HCl}(\mathrm{pH} 8) / 217 \mathrm{mM} \mathrm{Na}$ citrate $/ 1 \mathrm{M} \mathrm{NaCl} / 1 \mathrm{M} \mathrm{HCl}$ ] and $20 \mu \mathrm{L}$ aliquots of denatured DNAs were spotted onto nitrocellulose filters using a vacuum manifold. Filters were air-dried, washed twice with 6 X SSC $(0.9 \mathrm{M} \mathrm{NaCl} / 90 \mathrm{mM}$ Na citrate), air-dried, UV cross-linked at $254 \mathrm{~nm}$ for $3 \mathrm{~min}$, and baked for 2 hours at $80^{\circ} \mathrm{C}$.

Mitochondria at a protein concentration of $8.25 \mu \mathrm{g} / \mu \mathrm{L}$ were split into three $50 \mu \mathrm{L}$ aliquots; one sample was kept on ice, while the remaining aliquots were electroporated either in the absence or presence of plasmid \#819 at a field strength of $10 \mathrm{kV} / \mathrm{cm}$ as noted. Transcription reactions were carried out at $30{ }^{\circ} \mathrm{C}$ in $0.33 \mathrm{M}$ sucrose/20 mM Tris (pH 7.5)/20 mM MgCl $/ 10 \mathrm{mM} \mathrm{KCl} / 2 \mathrm{mM}$ DTT $/ 250 \mu \mathrm{M}$ ATP, CTP, and UTP/ $2 \mu \mathrm{M} \alpha^{32}$ P-GTP for $15 \mathrm{~min}$, then chased for 5 min with cold GTP as previously described [19]. Mitochondria were pelleted and total RNA was isolated with Zymo Spin IIC columns under conditions specified by the supplier to remove unincorporated nucleotides. After a $3 \mathrm{~h}$ pre-incubation of dot blot filters in hybridization buffer ( $0.5 \mathrm{M}$ sodium phosphate ( $\mathrm{pH} 7.2) / 1 \%$ BSA $/ 15 \%$ formamide/ $7 \%$ SDS/I mM EDTA), dot blots were incubated overnight with a fresh solution of hybridization buffer containing $4 \times 10^{5} \mathrm{cpm}$ labeled RNA per blot. Filters were washed once with 5 X SSC $/ 0.1 \%$ SDS, and twice with 2 X SSC $/ 0.1 \%$ SDS prior to visualization using a Typhoon 
phosphorimager (GE Healthcare, Life Sciences, Pittsburgh, PA, USA). Relative signal intensities were measured using ImageQuant software (Molecular Dynamics version 5.2, GE Healthcare, Life Sciences, Pittsburgh, PA, USA).

\subsection{RNA Editing Assay}

The presence of fully edited mitochondrial transcripts precludes assaying editing of newly synthesized RNA from endogenous genes via bulk RNA analysis, necessitating the use of labeling strategies. Transcripts were labeled under the same conditions used for the dot blot experiments, mitochondria were pelleted and total RNA was isolated with Zymo Spin IIC (Zymo Research, Irvine, CA, USA) columns. S1 nuclease protection and RNase T1 digestions were carried out as described by [34], using single stranded DNA complementary to the $3^{\prime}$ portion of the atpA mRNA as described in [17].

\section{Results}

\subsection{Efficient DNA Uptake upon Electroporation of Isolated P. polycephalum Mitochondria}

Electroporation methods require highly purified mitochondria in relatively high concentration. In order to isolate mitochondria in sufficient quantities, we first developed a new mitochondrial purification method (see Materials and Methods). To generate DNA constructs that could support transcription within P. polycephalum mitochondria, the portion of the mitochondrial genome that spans the transcription start site of the highly expressed ribosomal RNA operon was cloned for use in electroporation experiments (see Materials and Methods). Plasmid DNA and PCR fragments derived from this fusion construct were used to assess DNA uptake in optimization experiments.
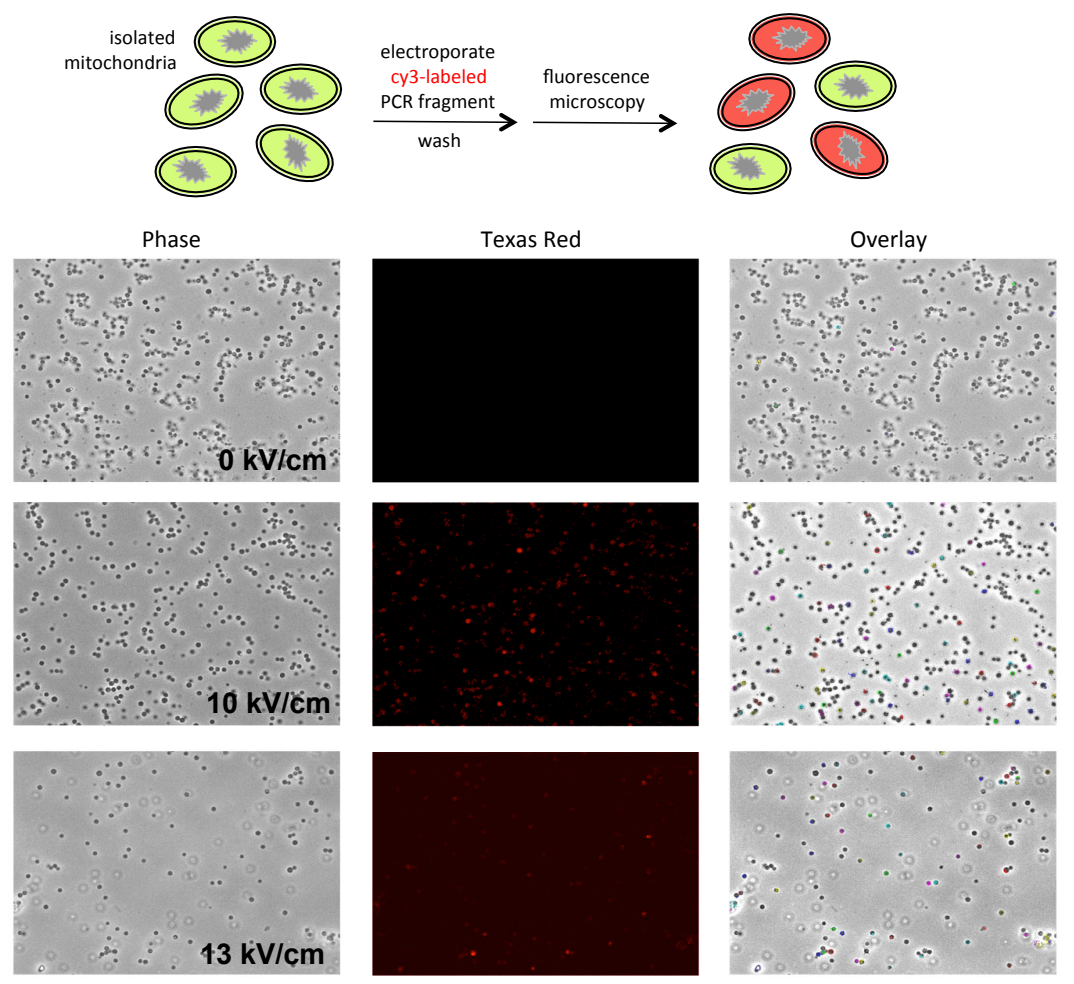

Figure 1. Uptake of cy3-labeled DNA into isolated mitochondria upon electroporation: (Top) Schematic representation of the experiment; and (Bottom) (left) phase contrast images of purified mitochondria incubated with a $847 \mathrm{bp}$ cy3-labeled PCR fragment without $(0 \mathrm{kV} / \mathrm{cm})$ or with electroporation at either $10 \mathrm{kV} / \mathrm{cm}$ or $13 \mathrm{kV} / \mathrm{cm}$; (center) visualization of cy3 fragment uptake via fluorescence microscopy; and (right) overlay of the fluorescent signals (shown in color) onto the respective phase images. 
To optimize electroporation conditions for P. polycephalum mitochondria, the efficiency of DNA uptake at different field strengths was assessed using a $847 \mathrm{bp}$ PCR fragment synthesized using a cy3-labeled DNA oligonucleotide. Uptake of the cy3-labeled PCR product by isolated P. polycephalum mitochondria was observed between 5 and $13 \mathrm{kV} / \mathrm{cm}$, with $10 \mathrm{kV} / \mathrm{cm}$ being optimal. In the experiment shown in Figure 1, the purified cy3-labeled DNA fragment was mixed with a suspension of isolated mitochondria and split into three tubes. One third of the mixture was not subjected to electroporation, one third was electroporated at $10 \mathrm{kV} / \mathrm{cm}$, and the final third was electroporated at $13 \mathrm{kV} / \mathrm{cm}$. Mitochondria were then washed to remove cy3-labeled DNA that was not taken up by the mitochondria prior to fluorescence microscopy. As can be seen in the center panel of Figure 1, background levels of fluorescence were extremely low in mitochondria that were not subjected to electroporation $(<5 \%)$. In contrast, efficient uptake of labeled DNA was observed upon electroporation at both $10 \mathrm{kV} / \mathrm{cm}$ $(\sim 85 \%)$ and $13 \mathrm{kV} / \mathrm{cm}(\sim 85 \%)$ (Figure 1, center). Some spots are clearly brighter than others, which could either be a function of depth of field or, potentially, the result of a greater amount of DNA being taken up in these mitochondria. Although only the brightest spots show up well on the overlay (Figure 1 right), virtually the entire fluorescent signal co-localizes with mitochondria (compare phase and Texas Red patterns in Figure 1). DNA uptake was $\sim 4-5$ fold lower at $5 \mathrm{kV} / \mathrm{cm}$ and $7.5 \mathrm{kV} / \mathrm{cm}$, while at field strengths above $12 \mathrm{kV} / \mathrm{cm}$ the number of intact mitochondria was significantly reduced (e.g., $13 \mathrm{kV} / \mathrm{cm}$ in Figure 1). These results demonstrate that DNA uptake under these conditions is highly efficient and is dependent upon electroporation.

\subsection{DNA Introduced into Mitochondria is Transcribed}

To determine whether the DNA taken up by P. polycephalum mitochondria is transcribed by the mitochondrial RNA polymerase, a plasmid containing the $L S U$-cox 1 fusion construct or the $847 \mathrm{bp}$ cy3-labeled PCR fragment derived from this construct was used for electroporation. Mitochondria were recovered, incubated under conditions that support robust RNA synthesis [35], and total mitochondrial RNA was isolated. cDNA synthesis and subsequent PCR was carried out using primers specific for the fusion construct to avoid amplifying endogenous transcripts. RT-PCR products of the expected size were produced from RNAs isolated from mitochondria electroporated in the presence of the PCR product (Figure 2A, lanes 2 and 4) or plasmid DNA (Figure 2B, lane 4). No signal was observed when reverse transcriptase was omitted from the cDNA synthesis reactions (Figure 2A,B, lanes 3, 5, 7), when DNA was omitted (Figure 2B, lane 6), or in the absence of electroporation (Figure 2A, lane 6 and Figure 2B, lane 2). RT-dependent PCR products of the correct size were observed over a range of DNA concentrations tested (30-500 ng of the PCR fragment, $0.5-1 \mu \mathrm{g}$ of a $3.9 \mathrm{kbp}$ plasmid DNA). These results demonstrate that DNA taken up upon electroporation is expressed as RNA.

\section{A. PCR fragment}

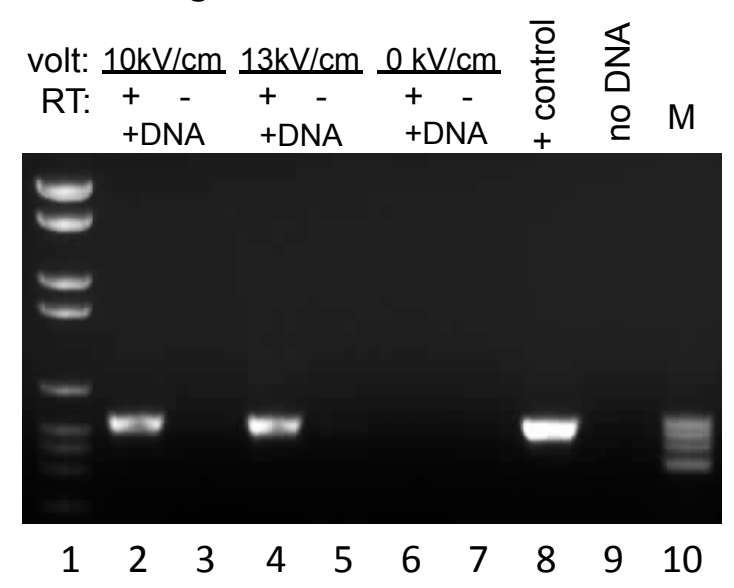

Figure 2. Cont. 


\section{B. plasmid DNA}

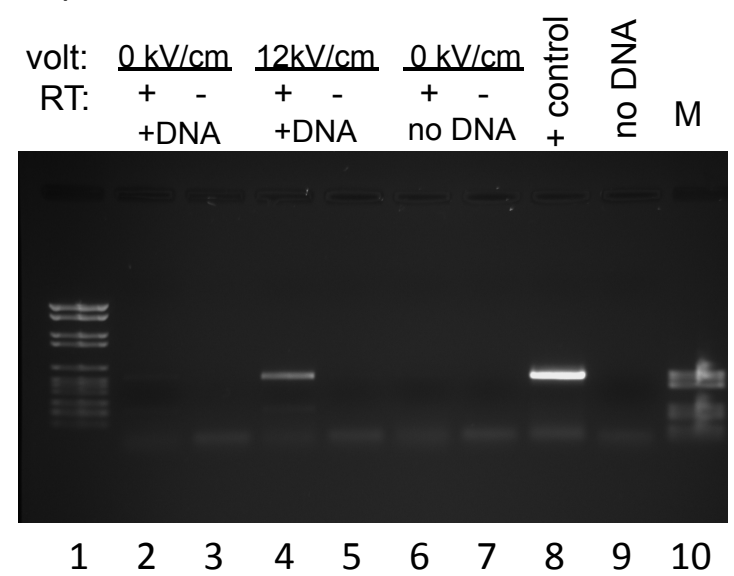

Figure 2. DNA introduced into mitochondria is transcribed: (A) Reverse transcription PCR (RT-PCR) products derived from RNA synthesized after incubation of isolated mitochondria with a $847 \mathrm{bp}$ cy3-labeled PCR fragment with $(10 \mathrm{kV} / \mathrm{cm}, 13 \mathrm{kV} / \mathrm{cm})$ or without $(0 \mathrm{kV} / \mathrm{cm})$ electroporation. The $+\mathrm{RT} /-\mathrm{RT}$ designation indicates reverse transcription reactions done in the presence or absence of enzyme, respectively. Lanes 1 and 10 contain size standards VI and V (Roche), respectively (M); PCR controls are shown in lanes 8 and 9. (B) RT-PCR products derived from RNA synthesized after incubation of isolated mitochondria with a $3.9 \mathrm{~kb}$ plasmid with $(12 \mathrm{kV} / \mathrm{cm})$ or without $(0 \mathrm{kV} / \mathrm{cm})$ electroporation. Samples in lanes 6 and 7 demonstrate the lack of background with total mitochondrial RNA (no exogenous DNA, no electroporation) with this set of plasmid-specific PCR primers. Other labels as in A.

\subsection{Transcripts Derived from DNA Introduced into Mitochondria Are Not Edited}

The constructs used in these experiments contain a total of 21 editing sites, including the first editing site within the large rRNA (LSU) and 20 editing sites within the cox1 region, which includes both insertion sites $(13+\mathrm{C}, 1+\mathrm{U}, 1+\mathrm{UA}$, and $1+\mathrm{CU}$ sites $)$ and 4 sites of $\mathrm{C}$ to $\mathrm{U}$ changes. This allowed us to examine the extent of editing at multiple types of editing sites. Use of an LSU-specific primer in the PCR reactions led to spurious bands arising from the endogenous rRNA, so RNA editing was only assessed at the 20 cox 1 editing sites. To determine whether the RNAs produced from DNA introduced into mitochondria were edited, bulk RT-PCR products derived from these transcripts were sequenced. No evidence of editing at any of the sites within the $\operatorname{cox} 1$ portion of the fusion transcript was observed under any of the conditions tested thus far (representative example shown in Figure S1). These include the conditions used in various plant mitochondrial electroporation experiments $[23,29,36]$ and conditions that support extensive RNA editing in P. polycephalum mitochondria $[19,35,37,38]$ (Figure S1).

\subsection{Electroporation Does Not Appreciatively Alter the Level of Transcription from Endogenous Genes}

Based on the lack of editing from exogenous templates, we next tested whether electroporation had a deleterious effect on endogenous gene expression. The level of transcription of 18 of the 20 transcripts identified in our analysis of the mitochondrial transcriptome (Figure 3A) was assessed. Newly synthesized transcripts were labeled to distinguish them from pre-existing RNA pools and used to probe dot blots loaded according to the grid shown in Figure 3B. In this series of experiments, mitochondria were isolated from microplasmodia and the suspension was divided into thirds. Run-on transcription was monitored by incorporation of $\alpha^{32}$ P-GTP into RNA in mitochondria not subjected to electroporation and mitochondria that had been electroporated in the absence or presence of exogenous DNA. To assess transcription levels relative to expression of endogenous genes, this plasmid (\#819) contained the mitochondrial LSU promoter driving expression of vector sequences. Total RNA was isolated and labeled RNA from each sample was used to probe individual dot blots 
on which PCR products from 19 mitochondrial genes, three nuclear genes, and the plasmid vector were immobilized. The relative level of gene expression was similar between the three samples (Figure 3C,D). Transcripts from all 19 mitochondrial genes were detected, with expression levels between genes varying over a 60-fold range, while spots corresponding to nuclear genes gave only background signal (Figure 3C,D). Upon prolonged exposure, an extremely low level of transcription from the plasmid sequences downstream of the $L S U$ promoter region was detected. Transcription from the introduced plasmid DNA was $\sim 7$-fold lower than the level of the weakest signal from an endogenous mitochondrial gene and was only present in mitochondria that had been electroporated in the presence of exogenous DNA, as expected. This is not surprising given that the signal from endogenous genes is primarily derived from run-on transcription of previously initiated transcripts, whereas the signal corresponding to vector sequences (pBSM13+) is solely due to newly initiated transcription from the LSU promoter inserted into the plasmid. These experiments indicate that electroporation does not significantly affect transcription from the mitochondrial genome.

A.

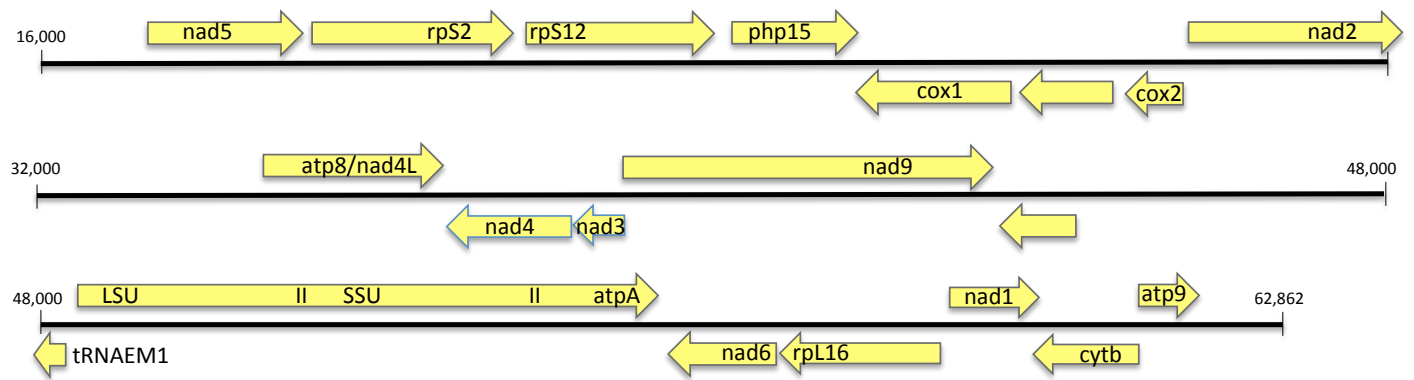

B.

\begin{tabular}{|c|c|c|c|c|c|c|c|}
\hline nad5 & rpS2 & rpS12 & php15 & cox1 & cox2 & nad2 & atp8/nad4L \\
$\mathbf{1}$ & 2 & 3 & 4 & 5 & $\mathbf{6}$ & $\mathbf{7}$ & $\mathbf{8}$ \\
\hline nad4 & nad3 & nad9 & tRNAEM1 & SSU & blank & atpA & nad6 \\
$\mathbf{9}$ & $\mathbf{1 0}$ & $\mathbf{1 1}$ & $\mathbf{1 2}$ & $\mathbf{1 3}$ & 14 & $\mathbf{1 5}$ & $\mathbf{1 6}$ \\
\hline rpL16 & nad1 & cytb & atp9 & tubulin & pBSM13+ & RNAP & glom2 \\
$\mathbf{1 7}$ & $\mathbf{1 8}$ & $\mathbf{1 9}$ & $\mathbf{2 0}$ & 21 & 22 & 23 & 24 \\
\hline
\end{tabular}

D.

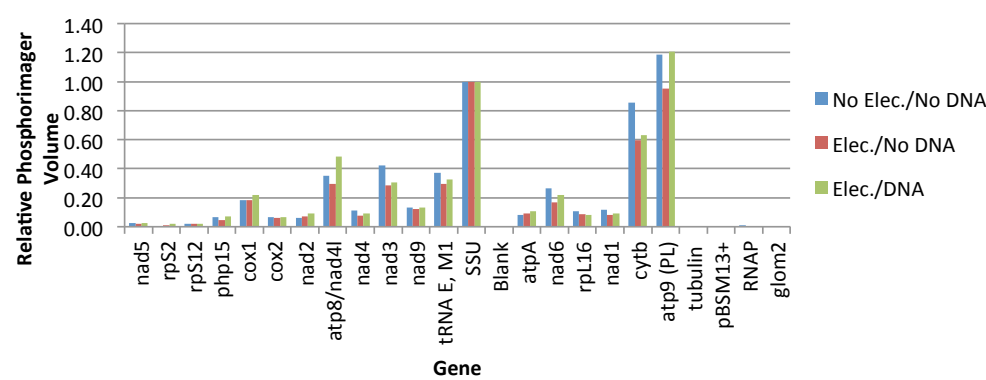

C.

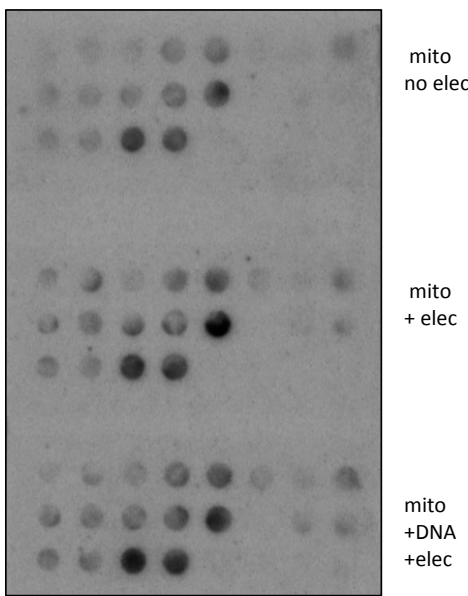

Figure 3. Transcription of endogenous genes is not altered by electroporation: (A) Transcript map of the genes probed in dot blot experiments using gene designations from [7]. (B) Grid positions of immobilized PCR fragments; (C) Dot blots probed with labeled RNA synthesized by: mitochondria before electroporation (top); mitochondria after electroporation in the absence of exogenous DNA (middle); and mitochondria after electroporation in the presence of exogenous DNA (bottom). (D) Quantification of the data in (C) showing relative expression levels of individual genes under each of the three conditions. 


\subsection{Insertional Editing Occurs within Transcripts from Endogenous Genes after Electroporation}

One potential explanation for the lack of insertion editing within transcripts synthesized from exogenous DNA was that electroporation disrupts editing in some way. To determine whether the editing apparatus is still functional after electroporation, editing was assessed in the pool of labeled run-on transcripts synthesized under the same conditions as those used for the dot blot analysis shown in Figure 3. To isolate transcripts from the endogenous atpA gene, total RNA from each sample was hybridized to single-stranded DNA complementary to a portion of the atpA mRNA, then digested with $\mathrm{S} 1$ nuclease. The protected region of the atpA mRNA was gel purified, digested with RNase T1, and the migration of the resulting fragments was compared to those from S1-protected unedited and edited control transcripts. As observed previously, transcripts made in isolated mitochondria prior to electroporation (Figure 4, lane 3) are fully edited, i.e., the migration of the diagnostic RNase T1 fragments indicated on the left matches those in the edited control (lane 2). Editing sites 52 (16/17mer) and $53(20 / 21 \mathrm{mer})$ are also fully edited in mitochondria after electroporation in either the absence $(\mathrm{M}+$, lanes 4 and 9) or presence (M + D, lanes 5 and 10) of plasmid DNA. Editing efficiency was reduced at sites 50 (29/30mer, $\sim 50 \%$ edited) and 54 (24/25mer, $\sim 85 \%$ edited) in the electroporated samples (lanes $4,5,9,10$ ), indicating that electroporation does have some effect on the editing machinery, at least at a subset of sites. However, substantial levels of editing are observed at all sites, demonstrating that mitochondria remain editing competent after electroporation. Thus, the lack of editing from exogenously supplied DNA cannot be simply due to global inactivation of the editing machinery.

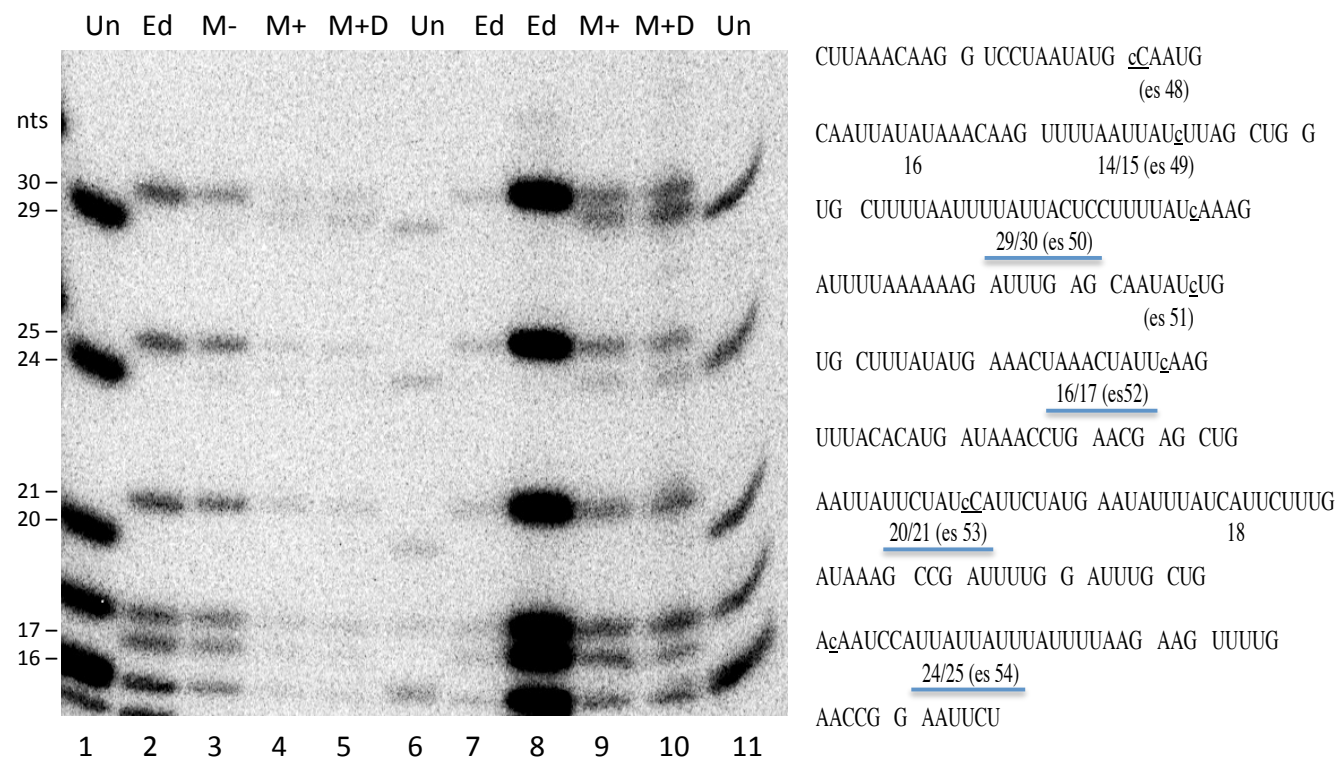

Figure 4. The editing machinery is still functional after electroporation. Gel electrophoresis of RNase T1 products generated from S1 nuclease-protected RNA fragments that encompass the last seven editing sites of the atpA mRNA. Internally labeled RNAs were synthesized by mitochondria before electroporation (M-, lane 3), mitochondria after electroporation in the absence of exogenous DNA $(\mathrm{M}+$, lanes 4 and 9), and mitochondria after electroporation in the presence of exogenous DNA $(\mathrm{M}+\mathrm{D}$, lanes 5 and 10). Different amounts of the same RNase T1 digests were loaded in lanes 4 and 9 and lanes 5 and 10. Multiple dilutions of RNase T1 digests of S1 nuclease-protected unedited (Un, lanes 1, 6, and 11) and edited (Ed, lanes 2, 7, and 8) control transcripts were run alongside for comparison. The sequence of the RNase T1 fragments from the protected region of the atpA mRNA is shown at the right, with the $C$ residue added at editing sites 48 through 54 (es48-es54) indicated by a lower case c. Easily resolvable RNase T1 fragments diagnostic of editing are underlined and the size in nucleotides (nts) of the edited and unedited fragments are indicated on the sequence and to the left of the gel. 


\section{Discussion}

Run-on transcripts synthesized in P. polycephalum mitochondria isolated via differential centrifugation with or without subsequent gradient purification are completely edited at most insertion sites under a range of transcription conditions [19,35,37,38]. However, mitochondrial yields are quite low upon secondary purification on Percoll gradients. In order to obtain sufficient quantities of mitochondria for electroporation experiments, a new purification scheme was developed. This involved the use of gentler lysis conditions, direct layering of filtered lysates onto Percoll step gradients, and minimization of applied centrifugal force (see Materials and Methods). Mitochondria purified in this way are free of contaminating nuclei, membranes, and pigment granules (Figure 1), are capable of taking up both linear and circular DNAs (Figures 1 and 2), express the normal complement of endogenous genes (Figure 3), and synthesize edited transcripts (Figure 4).

Electroporation methods have been developed for plant mitochondria from both monocots and dicots. Plasmid constructs introduced into mitochondria isolated from wheat embryos [23], etiolated maize seedlings [29], and potato tubers [31] support transcription, splicing, and C to U editing, providing a means of investigating editing signals $[22,25,26]$ and the interplay between different forms of RNA processing [27,29-31]. The studies in plant mitochondria utilized two distinct sets of electroporation and expression conditions, and variations of each were tested using isolated P. polycephalum mitochondria. None of these conditions supported editing of transcripts derived from DNA constructs introduced into P. polycephalum mitochondria. Switching to conditions known to support insertion editing in P. polycephalum mitochondria also failed to result in editing of transcripts from exogenous genes (Figure S1), despite the fact that native transcripts were largely edited under the same conditions (Figure 4). Curiously, although transcription from the mitochondrial genome was unaffected (Figure 3), electroporation reduced the level of editing at some sites but not others within the endogenous transcripts, although all sites examined were edited to at least $50 \%$. The reason for this is not clear, given that all sites were fully edited in untreated mitochondria processed in parallel (Figure 4). The finding that cells electroporated in the absence or presence of DNA both yielded the same editing pattern, with some sites being fully edited, argues against the possibility that editing is only affected in the $\sim 85 \%$ of mitochondria that have taken up DNA.

The inability of DNA introduced into isolated P. polycephalum mitochondria to support editing may be due to the lack of associated editing factors. We have previously demonstrated that insertion editing requires a factor or factors associated with the P. polycephalum mitochondrial genome [39]. Fractionation of mitochondrial lysates over a gel filtration column yields crude mitochondrial transcription elongation complexes (mtTECs) that are editing competent [18]. The DNA in these complexes can be digested with restriction enzymes and the resulting fragments can be ligated to create chimeric templates. RNAs produced from intra- and inter-genic fusions are edited to the same extent as RNAs produced by mtTECs. However, when exogenous DNA fragments are ligated to digested mtTEC fragments, the portion of the run-on RNAs produced from the native template is edited, but the portion derived from the added DNA is not. Importantly, the same is true when deproteinized fragments of P. polycephalum mitochondrial DNA are fused to mtTEC templates, strongly suggesting a role for a DNA-bound factor(s) [39].

The lack of editing in transcripts derived from exogenous templates is unlikely to be due to context effects based on our previous work with chimeric templates, which utilized dozens of intraand intergenic chimeras, including rRNA-rRNA, mRNA-mRNA, and rRNA-mRNA fusions [20,39,40]. Using chimeric templates with junctions very close to editing sites, we demonstrated that the cis-acting elements required for the insertion of non-encoded nucleotides are limited to template sequences within $9 \mathrm{bp}$ upstream and $9-10 \mathrm{bp}$ downstream of an editing site [20]. Template changes outside of this critical region had no effect on the level of editing at any site within the chimeric RNAs, many of which contained sequences derived from the LSU gene. Thus, even if inclusion of LSU sequences upstream of the $\operatorname{cox} 1$ region resulted in inhibitory RNA structures, there is no reason to believe that all 20 of the downstream editing sites would be negatively affected. 
The work presented here was initiated to determine whether a lack of editing factors could be overcome by expressing exogenous DNA templates within the confines of isolated mitochondria. The finding that editing was not observed when either linear or circular DNA was introduced into mitochondria and transcribed under a variety of conditions may be due to the absence of some component needed for de novo assembly of editing complexes. Additional conditions, such as inclusion of amino acids to support new protein synthesis, will be explored in future studies.

Supplementary Materials: The following supplementary materials can be found online at www.mdpi.com/20734425/7/12/128/s1, Figure S1: Transcripts from DNA introduced into mitochondria are not edited. Sequence trace of the bulk RT-PCR product shown in lane 4 of Figure 2B (shown again at the top of this figure). The positions of cox1 editing sites (es) 22-43 and the 5 bp block mutation (block $\mathrm{mt}$ ) are indicated on the trace. Black arrowheads represent sites where nucleotides are normally added to mitochondrial transcripts (including 1 single U insertion site, 13 single $C$ insertion sites, and the UA and UC insertion sites); blue arrowheads represent the 4 sites of expected $\mathrm{C}$ to $\mathrm{U}$ changes. No editing is observed at any of these sites, Table S1: Oligonucleotides used to generate PCR fragments immobilized on dot blot filters.

Acknowledgments: The authors wish to thank Dylan Simon, Nicole Cremona and Tereena Marks for technical assistance; Nicole Cremona and Jillian Houtz for critical reading of the manuscript; and Suzanne Brady-Kalnay for microscope access. This work was supported by National Science Foundation grants MCB-1243687 and MCB-1616411 to J.M.G. Support for S.J.H. is provided by the Visual Sciences Research Center Core grant P30-EY11373 from the National Eye Institute.

Author Contributions: J.M.G. conceived and designed the experiments and performed the experiments and data analysis for Figures 2 and 4. G.M.N. performed the experiment and analyzed the data in Figure 3. S.J.H. carried out the microscopy and provided the images shown in Figure 1, including the overlay of the fluorescence and phase signals. J.M.G. wrote the manuscript.

Conflicts of Interest: The authors declare no conflict of interest.

\section{References}

1. Knoop, V. When you can't trust the DNA: RNA editing changes transcript sequences. Cell. Mol. Life Sci. 2011, 68, 567-586. [CrossRef] [PubMed]

2. Gott, J.M.; Emeson, R.B. Functions and mechanisms of RNA editing. Annu. Rev. Genet. 2000, 34, 499-531. [CrossRef] [PubMed]

3. Takenaka, M.; Zehrmann, A.; Verbitskiy, D.; Hartel, B.; Brennicke, A. RNA editing in plants and its evolution. Annu. Rev. Genet. 2013, 47, 335-352. [CrossRef] [PubMed]

4. Jackson, C.J.; Norman, J.E.; Schnare, M.N.; Gray, M.W.; Keeling, P.J.; Waller, R.F. Broad genomic and transcriptional analysis reveals a highly derived genome in dinoflagellate mitochondria. BMC Biol. 2007, 5, 41. [CrossRef] [PubMed]

5. Lin, S.; Zhang, H.; Spencer, D.F.; Norman, J.E.; Gray, M.W. Widespread and extensive editing of mitochondrial mRNAs in dinoflagellates. J. Mol. Biol. 2002, 320, 727-739. [CrossRef]

6. Simpson, L.; Wang, S.H.; Thiemann, O.H.; Alfonzo, J.D.; Maslov, D.A.; Avila, H.A. U-insertion/deletion edited sequence database. Nucleic Acids Res. 1998, 26, 170-176. [CrossRef] [PubMed]

7. Bundschuh, R.; Altmuller, J.; Becker, C.; Nurnberg, P.; Gott, J.M. Complete characterization of the edited transcriptome of the mitochondrion of Physarum polycephalum using deep sequencing of RNA. Nucleic Acids Res. 2011, 39, 6044-6055. [CrossRef] [PubMed]

8. Gott, J.M. Mechanisms and functions of RNA editing in Physarum polycephalum. In RNA Editing: Current Research and Future Trends; Mass, S., Ed.; Horizon Press: Norwich, UK, 2013; pp. 17-40.

9. Gott, J.M.; Parimi, N.; Bundschuh, R. Discovery of new genes and deletion editing in Physarum mitochondria enabled by a novel algorithm for finding edited mRNAs. Nucleic Acids Res. 2005, 33, 5063-5072. [CrossRef] [PubMed]

10. Gott, J.M.; Somerlot, B.H.; Gray, M.W. Two forms of RNA editing are required for tRNA maturation in Physarum mitochondria. RNA 2010, 16, 482-488. [CrossRef] [PubMed]

11. Gott, J.M.; Visomirski, L.M.; Hunter, J.L. Substitutional and insertional RNA editing of the cytochrome c oxidase subunit 1 mRNA of Physarum polycephalum. J. Biol. Chem. 1993, 268, 25483-25486. [PubMed] 
12. Antes, T.; Costandy, H.; Mahendran, R.; Spottswood, M.; Miller, D. Insertional editing of mitochondrial tRNAs of Physarum polycephalum and Didymium nigripes. Mol. Cell. Biol. 1998, 18, 7521-7527. [CrossRef] [PubMed]

13. Bullerwell, C.E.; Burger, G.; Gott, J.M.; Kourennaia, O.; Schnare, M.N.; Gray, M.W. Abundant 5s rRNA-like transcripts encoded by the mitochondrial genome in amoebozoa. Eukaryot. Cell 2010, 9, 762-773. [CrossRef] [PubMed]

14. Mahendran, R.; Spottswood, M.R.; Miller, D.L. RNA editing by cytidine insertion in mitochondria of Physarum polycephalum. Nature 1991, 349, 434-438. [CrossRef] [PubMed]

15. Mahendran, R.; Spottswood, M.S.; Ghate, A.; Ling, M.L.; Jeng, K.; Miller, D.L. Editing of the mitochondrial small subunit rRNA in Physarum polycephalum. EMBO J. 1994, 13, 232-240. [PubMed]

16. Wang, S.S.; Mahendran, R.; Miller, D.L. Editing of cytochrome b mRNA in Physarum mitochondria. J. Biol. Chem. 1999, 274, 2725-2731. [CrossRef] [PubMed]

17. Cheng, Y.W.; Visomirski-Robic, L.M.; Gott, J.M. Non-templated addition of nucleotides to the $3^{\prime}$ end of nascent RNA during RNA editing in Physarum. EMBO J. 2001, 20, 1405-1414. [CrossRef] [PubMed]

18. Cheng, Y.W.; Gott, J.M. Transcription and RNA editing in a soluble in vitro system from Physarum mitochondria. Nucleic Acids Res. 2000, 28, 3695-3701. [CrossRef] [PubMed]

19. Visomirski-Robic, L.M.; Gott, J.M. Accurate and efficient insertional RNA editing in isolated Physarum mitochondria. RNA 1995, 1, 681-691. [PubMed]

20. Rhee, A.C.; Somerlot, B.H.; Parimi, N.; Gott, J.M. Distinct roles for sequences upstream of and downstream from Physarum editing sites. RNA 2009, 15, 1753-1765. [CrossRef] [PubMed]

21. Collombet, J.M.; Wheeler, V.C.; Vogel, F.; Coutelle, C. Introduction of plasmid DNA into isolated mitochondria by electroporation. A novel approach toward gene correction for mitochondrial disorders. J. Biol. Chem. 1997, 272, 5342-5347. [CrossRef] [PubMed]

22. Castandet, B.; Araya, A. The RNA editing pattern of cox $2 \mathrm{mRNA}$ is affected by point mutations in plant mitochondria. PLoS ONE 2011, 6, e20867. [CrossRef] [PubMed]

23. Farre, J.C.; Araya, A. Gene expression in isolated plant mitochondria: High fidelity of transcription, splicing and editing of a transgene product in electroporated organelles. Nucleic Acids Res. 2001, 29, 2484-2491. [CrossRef] [PubMed]

24. Farre, J.C.; Araya, A. RNA splicing in higher plant mitochondria: Determination of functional elements in group II intron from a chimeric cox II gene in electroporated wheat mitochondria. Plant J. 2002, 29, $203-213$. [CrossRef] [PubMed]

25. Farre, J.C.; Leon, G.; Jordana, X.; Araya, A. Cis recognition elements in plant mitochondrion RNA editing. Mol. Cell. Biol. 2001, 21, 6731-6737. [CrossRef] [PubMed]

26. Choury, D.; Farre, J.C.; Jordana, X.; Araya, A. Different patterns in the recognition of editing sites in plant mitochondria. Nucleic Acids Res. 2004, 32, 6397-6406. [CrossRef] [PubMed]

27. Farre, J.C.; Aknin, C.; Araya, A.; Castandet, B. RNA editing in mitochondrial trans-introns is required for splicing. PLoS ONE 2012, 7, e52644. [CrossRef] [PubMed]

28. Staudinger, M.; Bolle, N.; Kempken, F. Mitochondrial electroporation and in organello RNA editing of chimeric atp6 transcripts. Mol. Genet. Genom. 2005, 273, 130-136. [CrossRef] [PubMed]

29. Staudinger, M.; Kempken, F. Electroporation of isolated higher-plant mitochondria: Transcripts of an introduced cox2 gene, but not an atp6 gene, are edited in organello. Mol. Genet. Genom. 2003, 269, 553-561. [CrossRef] [PubMed]

30. Castandet, B.; Choury, D.; Begu, D.; Jordana, X.; Araya, A. Intron RNA editing is essential for splicing in plant mitochondria. Nucleic Acids Res. 2010, 38, 7112-7121. [CrossRef] [PubMed]

31. Choury, D.; Farre, J.C.; Jordana, X.; Araya, A. Gene expression studies in isolated mitochondria: Solanum tuberosum rps10 is recognized by cognate potato but not by the transcription, splicing and editing machinery of wheat mitochondria. Nucleic Acids Res. 2005, 33, 7058-7065. [CrossRef] [PubMed]

32. Daniel, J.W.; Baldwin, H.H. Methods of culture for plasmodial myxomycetes. In Methods in Cell Physiology; Prescott, D.M., Ed.; Academic Press: New York, NY, USA, 1964; Volume 1, pp. 9-41.

33. Mohberg, J. Preparation of spherules. In Cell Biology of Physarum and Didymium: Differentiation, Metabolism, and Methodology; Aldruch, H.C., Daniel, J.W., Eds.; Academic Press: New York, NY, USA, 1982; Volume II, pp. 241-243. 
34. Byrne, E.M.; Visomirski-Robic, L.; Cheng, Y.W.; Rhee, A.C.; Gott, J.M. RNA editing in Physarum mitochondria: Assays and biochemical approaches. Methods Enzymol. 2007, 424, 143-172. [PubMed]

35. Visomirski-Robic, L.M.; Gott, J.M. Insertional editing in isolated Physarum mitochondria is linked to RNA synthesis. RNA 1997, 3, 821-837. [PubMed]

36. Farre, J.C.; Choury, D.; Araya, A. In organello gene expression and RNA editing studies by electroporation-mediated transformation of isolated plant mitochondria. Methods Enzymol. 2007, 424, 483-500. [PubMed]

37. Byrne, E.M.; Gott, J.M. Unexpectedly complex editing patterns at dinucleotide insertion sites in Physarum mitochondria. Mol. Cell. Biol. 2004, 24, 7821-7828. [CrossRef] [PubMed]

38. Visomirski-Robic, L.M.; Gott, J.M. Insertional editing of nascent mitochondrial RNAs in Physarum. Proc. Natl. Acad. Sci. USA 1997, 94, 4324-4329. [CrossRef] [PubMed]

39. Byrne, E.M.; Gott, J.M. Cotranscriptional editing of Physarum mitochondrial RNA requires local features of the native template. RNA 2002, 8, 1174-1185. [CrossRef] [PubMed]

40. Byrne, E.M.; Stout, A.; Gott, J.M. Editing site recognition and nucleotide insertion are separable processes in Physarum mitochondria. EMBO J. 2002, 21, 6154-6161. [CrossRef] [PubMed]

(C) 2016 by the authors; licensee MDPI, Basel, Switzerland. This article is an open access article distributed under the terms and conditions of the Creative Commons Attribution (CC-BY) license (http://creativecommons.org/licenses/by/4.0/). 